Research Article

\title{
Low-Temperature Performance and Evaluation Index of Gussasphalt for Steel Bridge Decks
}

\author{
Hongyu Ye, ${ }^{1}$ Xuancang Wang $\mathbb{D}^{1},{ }^{1}$ Naren Fang, ${ }^{1}$ and Ziyuan $\mathrm{Su}^{2}$ \\ ${ }^{1}$ School of Highway Engineering, Chang'an University, Xi'an 710064, China \\ ${ }^{2}$ Hunan Provincial Communications Planing Survey \& Design Institute, Changsha 410000, China \\ Correspondence should be addressed to Xuancang Wang; wxc2005@chd.edu.cn
}

Received 18 October 2018; Revised 19 December 2018; Accepted 14 January 2019; Published 25 February 2019

Academic Editor: Antonio Caggiano

Copyright (c) 2019 Hongyu Ye et al. This is an open access article distributed under the Creative Commons Attribution License, which permits unrestricted use, distribution, and reproduction in any medium, provided the original work is properly cited.

Gussasphalt is widely used in steel deck pavement in cold regions; thus, it should have good low-temperature performance. A method for evaluating the low-temperature performance of gussasphalt is presented in this paper. Low-temperature bending, bending creep, and splitting tests were used to study the performance of different types of gussasphalt. The sensitivity and correlation between low-temperature indices obtained from three methods were compared and analyzed with sensitivity factors and the grey relational coefficient, respectively, and the low-temperature evaluation index and standard of gussasphalt in cold regions were determined. Flow, penetration at $50^{\circ} \mathrm{C}$, low-temperature bending, and bending fatigue tests of the trabeculae were carried out after secondary mixing of gussasphalt asphalt concrete. Degradation of the material performance after different storage times was studied. Finally, taking the strain energy density as the main control index and considering the fluidity, the hightemperature performance, fatigue characteristics, technical requirements for storage, and mixing time of gussasphalt in cold weather after two mixing procedures are discussed.

\section{Introduction}

Gussasphalt (GA) is widely employed in the construction of steel bridge deck pavement due to its ability to form via selfflow without compaction, its high compactness after forming, water resistance, and good compatibility with steel deck plate deformation [1-4]. The wide application of GA in cold areas motivates the development of methods for evaluating its low-temperature performance [5-7].

Scholars have conducted research on the lowtemperature performance of asphalt mixtures and their evaluation indices [8-10]. The US SARP Program proposed using the low-temperature bending Young's modulus and creep strain rate [11]. Pszczola et al. [12] used a bending beam creep test to evaluate the low-temperature performance of asphalt mixtures. Fan et al. [13] evaluated the low-temperature performance of asphalt concrete using a semicircle bending (SCB) test. Wu et al. [14] analyzed the high-temperature performance and low-temperature performance of layered silicate modified asphalt concrete with a three-point bending test, rutting test, and SHRP rutting test. Gao et al. [15] used indirect tensile tests to evaluate the low-temperature performance of asphaltconcrete containing basalt fiber. Morea et al. [16] used the wheel tracking test (WTT) to evaluate the rut performance of materials with a given gradation and different binders. Pei et al. [17] analyzed the contribution of steel fibers to the crack resistance of asphalt concrete at various temperatures with trabecular bending tests. Hao and Liu [18] explored the low-temperature performance of asphalt mixtures using restrained stress tests and proposed evaluating the low-temperature crack resistance of an asphalt mixture based on frost crack stress. Yang et al. [19] conducted laboratory tests and concluded that the lowtemperature stiffness of an asphalt mixture can be used to accurately evaluate crack resistance of ordinary asphalt mixtures at low temperature. Liu et al. [20] proposed that the bending strain energy density and freeze-break temperature obtained from low-temperature bending tests can be used to characterize the low-temperature performance 
of a superpave mixture. Although aforementioned research includes a series of studies that focused on the lowtemperature performance of the mixture in China and foreign countries, there is still no unified standard control index for evaluating low-temperature design of GA mixture $[21,22]$, especially regarding the use of GA as pavement material in steel bridge decks. Determining an appropriate index for low-temperature performance that can ensure the pavement material can meet the needs of different regions is an urgent problem to be solved [23].

Aiming at the problem of insufficient research on the low-temperature performance of GA in cold areas, the lowtemperature performance of GA with $15 \%$ and $30 \%$ Trinidad Lake asphalt (TLA) admixtures by weight and three types of GA gradations was studied using low-temperature bending, bending creep, and low-temperature splitting tests. Evaluation methods and indices were determined by analyzing the correlation between different low-temperature evaluation indices and their sensitivities to different gradations and TLA ratios. Fluidity, penetration at $50^{\circ} \mathrm{C}$, low-temperature bending, and trabecular bending fatigue tests of GA after secondary mixing were applied to samples taken from a GA transport vehicle (COOKER). The degradation of GA after various storage and mixing times was examined. The storage time, mixing time, and technical requirements of GA in cold areas were determined.

\section{Low-Temperature Performance Test of GA}

2.1. Technical Properties of Raw Materials. Modified asphalt + TLA was used as an asphalt binder, and two TLA ratios with total weight of $15 \%$ and $30 \%$ were used for blending. The technical indicators of GA are shown in Table 1 . The properties of the aggregate and mineral powder are shown in Tables 2-4.

\subsection{Gradation Selection}

2.2.1. Gradation. GA10 refers to GA with $9.5 \mathrm{~mm}$ maximum aggregate size. The rate of GA10 aggregate passing through key sieve holes (defined as $2.36 \mathrm{~mm}$ and $1.18 \mathrm{~mm}$ ) was adjusted based on the median aggregate size $[22,24,25]$. We subsequently proposed three gradation schemes. The passage rate and gradation curve of the aggregate sieve holes are shown in Figure 1.

The gradation curve shows that gradation 1 exhibits higher passing rate through all sieve holes based on the median gradation value, and the proportion of fine aggregate is higher. Gradation 2 exhibits lower passing rate through all sieve holes based on the median gradation value, and the proportion of coarse aggregate is higher. Gradation 3 has a larger passing rate through key sieve holes $(2.36 \mathrm{~mm}$ and $1.18 \mathrm{~mm})$ based on the median gradation value.

2.2.2. Asphalt Content. Aggregates with gradations 1, 2, and 3 were selected for further testing. Referring to a survey in the literature [26], the optimum asphalt content
TABle 1: Technical indicators of GA.

\begin{tabular}{|c|c|c|c|}
\hline \multirow[b]{2}{*}{ Technical indicators } & \multicolumn{2}{|c|}{ Test value } & \multirow{2}{*}{$\begin{array}{c}\text { Standard } \\
{[24]}\end{array}$} \\
\hline & $15 \%$ & $30 \%$ & \\
\hline $\begin{array}{l}\text { Penetration }\left(25^{\circ} \mathrm{C}, 5 \mathrm{~s}, 100 \mathrm{~g}\right) \\
(0.1 \mathrm{~mm})\end{array}$ & 29.4 & 17 & $10 \sim 40$ \\
\hline Ductility $\left(10^{\circ} \mathrm{C}\right)(\mathrm{cm})$ & 22.0 & 12.4 & $\geq 10$ \\
\hline Softening point $(\mathrm{R} \& \mathrm{~B})\left({ }^{\circ} \mathrm{C}\right)$ & 86.0 & 90.2 & $\geq 72$ \\
\hline Flash point (Cleveland open cup) $\left({ }^{\circ} \mathrm{C}\right)$ & 275 & 289 & $\geq 240$ \\
\hline Density $\rho_{15^{\circ} \mathrm{C}}\left(\mathrm{g} / \mathrm{cm}^{3}\right)$ & 1.110 & 1.121 & $\geq 1.00$ \\
\hline
\end{tabular}

TABLE 2: Technical index of coarse aggregate.

\begin{tabular}{lcccc}
\hline $\begin{array}{l}\text { Technical } \\
\text { indicators }\end{array}$ & $\begin{array}{c}\text { Test value } \\
\mathrm{mm}\end{array}$ & $\begin{array}{c}4.75 \sim 9.5 \\
\mathrm{~mm}\end{array}$ & $\begin{array}{c}9.5 \sim 13.2 \\
\mathrm{~mm}\end{array}$ & $\begin{array}{c}\text { Standard } \\
{[24]}\end{array}$ \\
\hline $\begin{array}{l}\text { Apparent density } \\
\left(\mathrm{g} / \mathrm{cm}^{3}\right)\end{array}$ & 2.870 & 2.877 & 2.890 & $\geq 2.60$ \\
$\begin{array}{l}\text { Bulk volume density } \\
\left(\mathrm{g} / \mathrm{cm}^{3}\right)\end{array}$ & 2.838 & 2.870 & 2.880 & - \\
$\begin{array}{l}\text { Crushing value of } \\
\text { stone (\%) }\end{array}$ & - & - & 10.9 & $\leq 26$ \\
$\begin{array}{l}\text { Abrasion value (\%) } \\
\text { Water absorption (\%) }\end{array}$ & -0.40 & 0.50 & 0.96 & $\leq 2.0$ \\
$\begin{array}{l}\text { Sturdiness (\%) } \\
\text { Needle and plate }\end{array}$ & 3.23 & 1.12 & 2.4 & $\leq 12$ \\
$\begin{array}{l}\text { particle content (\%) } \\
\text { Water washing }\end{array}$ & - & 2.64 & 3.1 & $\leq 15$ \\
$\begin{array}{l}\text { method <0.075 mm } \\
\text { particle content }(\%)\end{array}$ & 0.3 & 0.4 & 0.3 & $\leq 1$ \\
Soft rock content $(\%)$ & - & 0.31 & 0.7 & $\leq 3$ \\
\hline
\end{tabular}

TABle 3: Technical index of coarse aggregate.

\begin{tabular}{lcc}
\hline Technical indicators & Test value & Standard [24] \\
\hline Apparent density $\left(\mathrm{g} / \mathrm{cm}^{3}\right)$ & 2.920 & $\geq 2.60$ \\
Angularity (s) & 51.2 & $\geq 30$ \\
Sand equivalent $(\%)$ & 88 & $\geq 60$ \\
\hline
\end{tabular}

TABle 4: Technical index of mineral powder.

\begin{tabular}{lcc}
\hline Technical indicators & Test value & Standard [24] \\
\hline Apparent density $\left(\mathrm{g} / \mathrm{cm}^{3}\right)$ & 2.730 & $\geq 2.50$ \\
Water absorption $(\%)$ & 0.10 & $\leq 1.0$ \\
Particle size range $(\%)$ & & \\
$\quad<0.6 \mathrm{~mm}$ & 100 & 100 \\
$<0.15 \mathrm{~mm}$ & 98.5 & $90 \sim 100$ \\
$<0.075 \mathrm{~mm}$ & 95.6 & $75 \sim 100$ \\
Hydrophilic coefficient & 0.52 & $<1$ \\
\hline
\end{tabular}

was determined from fluidity [27] and penetration tests at $40^{\circ} \mathrm{C}$ for asphalt-concrete ratios of $8.2 \%, 8.5 \%, 8.8 \%$, and $9.1 \%$.

Penetration tests were conducted at $40^{\circ} \mathrm{C}$ with a penetration tester. $70.7 \times 70.7 \times 70.7 \mathrm{~mm}^{3}$ specimens were placed in a water bath at $40^{\circ} \mathrm{C}$ for $1 \mathrm{~h}$. First, a $20 \mathrm{~N}$ load was applied to the specimens, and the dial indicator was adjusted to zero. Then, a $490.5 \mathrm{~N}$ load was applied to the specimens, and the dial indicator readings were recorded at different times 


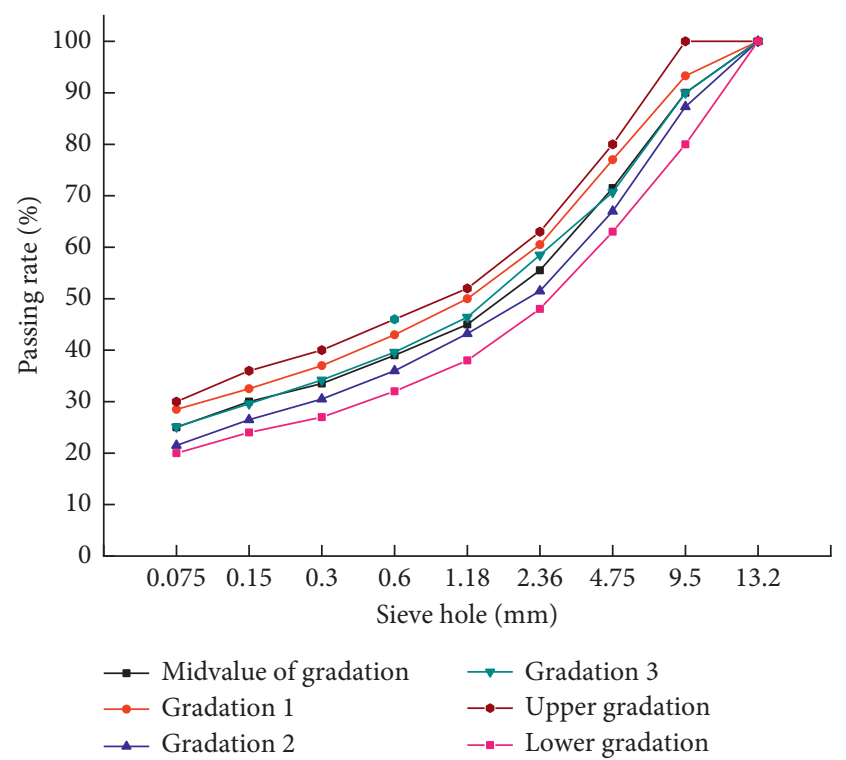

Figure 1: Passing rate curve for various GA gradations.

(from $1 \mathrm{~min}$ to $60 \mathrm{~min}$ ). The penetration rate at $30 \mathrm{~min}$ was taken as a baseline penetration rate, and the difference between the penetration rates at $60 \mathrm{~min}$ and $30 \mathrm{~min}$ is defined as the penetration increment. The test instruments and specimens are shown in Figure 2.

According to the Japanese pavement test method [26], the fluidity of GA should range from 3 to $20 \mathrm{~s}$ and the penetration should range from 1 to $4 \mathrm{~mm}$. The fluidity and penetration of GA were determined to be $16 \mathrm{~s}$ and $1.5 \mathrm{~mm}$, respectively.

The fluidity and penetration test results at $40^{\circ} \mathrm{C}$ are shown in Figure 3.

Figure 3 shows that the average asphalt-concrete ratios in gradations 1,2 , and 3 are $8.49 \%, 8.53 \%$, and $8.50 \%$, respectively. The average value of the optimum asphalt content determined from the three gradations was $8.5 \%$. Therefore, an asphalt-concrete ratio of $8.5 \%$ was chosen as the best value for further testing.

2.2.3. Test Scheme. According to the proportion of lake asphalt used in GA, asphalt materials are divided into 15\% TLA $+85 \%$ modified asphalt and 30\% TLA $+70 \%$ modified asphalt. Table 5 shows six schemes that were used to test asphalt mixtures prepared with an $8.5 \%$ oil-stone ratio and the three gradations listed.

2.3. Test Method. Each sample was tested using the above 6 test schemes.

2.3.1. Low-Temperature Bending Test. Low-temperature bending tests were performed using an electronic universal testing machine. The test instrument is shown in Figure 4. A $300 \times 100 \times 50 \mathrm{~mm}^{3}$ beam specimen was placed in an environmental box, and the temperature was maintained at $-10^{\circ} \mathrm{C}$ for $1 \mathrm{~h}$. A $1 \mathrm{kN}$ load was applied in the center of the

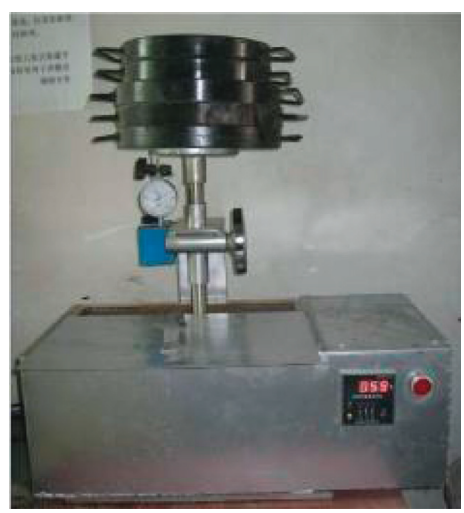

(a)

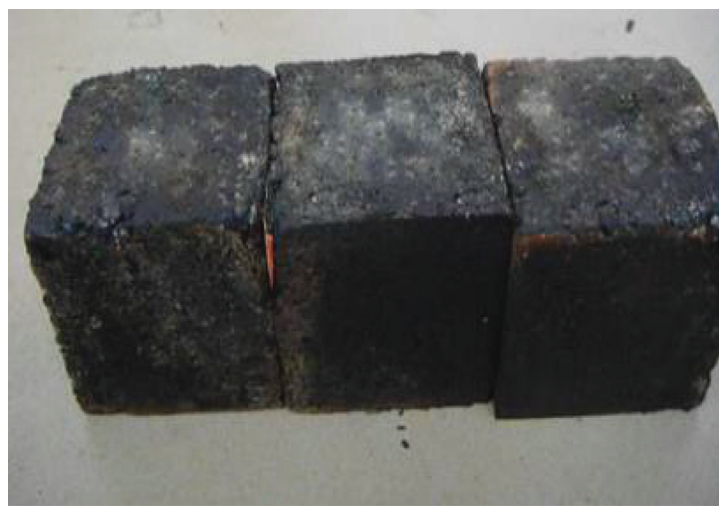

(b)

Figure 2: (a) Penetration test apparatus and (b) specimens.

span at $50 \mathrm{~mm} / \mathrm{min}$ until the specimen was destroyed $[24,28]$. The test was repeated five times.

In order to comprehensively reflect the strength and strain of the pavement materials, the ultimate bending strain energy density was added as a comprehensive index to reflect the bending tensile strength and strain of GA from an energy perspective.

The area enclosed by the stress-strain curve up to the peak value along the curve is the ultimate bending strain energy density of the GA mixture, as shown in Figure 5.

The bending tensile strength, bending tensile strain, and ultimate bending strain energy density were determined using the stress-strain curve obtained from the lowtemperature bending test.

2.3.2. Bending Creep Test. The bending creep test was performed using an electronic universal testing machine. Bending tests were conducted at $0^{\circ} \mathrm{C}$ using $250 \times 30 \times 35 \mathrm{~mm}^{3}$ trabecular specimens, and the flexural tensile strength was tested in each scheme. $10 \%$ of the corresponding flexural tensile strength was selected as the test load for each specimen, and the trabecular specimens were tested at $0^{\circ} \mathrm{C}$ in each scheme. The stable period in the deformation curve during the test was allowed to exceed $20 \mathrm{~min}$. The resulting bending creep rate was measured and calculated $[24,28]$. The test was repeated five times. 


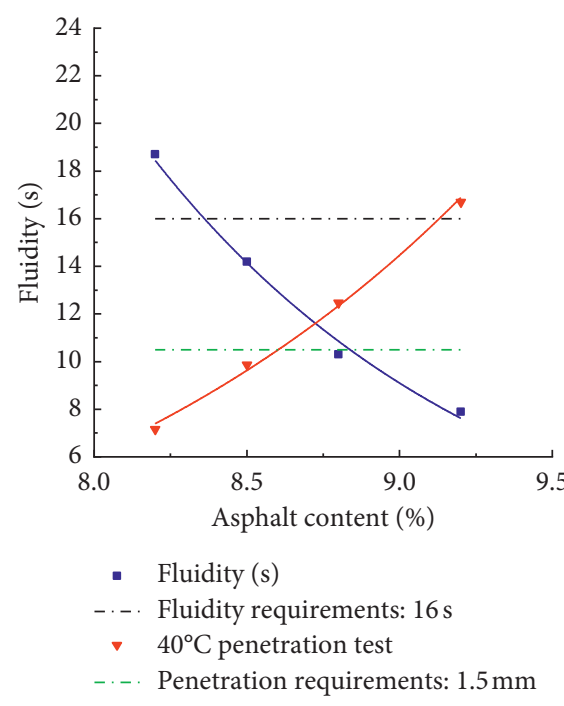

(a)

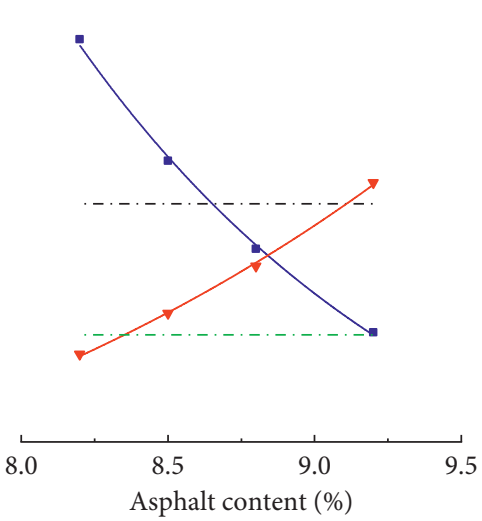

- Fluidity (s)

-... Fluidity requirements: $16 \mathrm{~s}$

- $40^{\circ} \mathrm{C}$ penetration test

_. Penetration requirements: $1.5 \mathrm{~mm}$

(b)

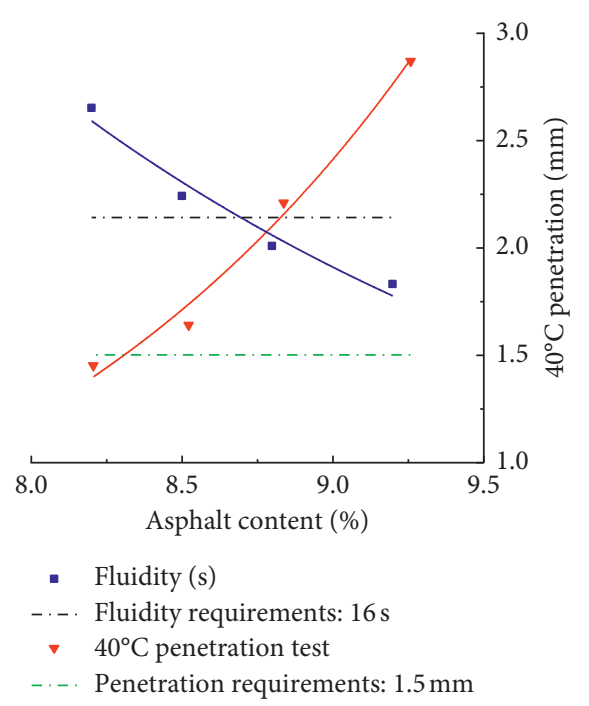

(c)

FIGURE 3: Relationship between fluidity and penetration in GA samples with different asphalt-concrete ratios: (a) gradation 1, (b) gradation 2 , and (c) gradation 3.

TABLE 5: Schemes for testing the low-temperature performance of GA.

\begin{tabular}{lcc}
\hline Test scheme & Asphalt mixing ratio & Gradation types \\
\hline Scheme 1 & & Gradation 1 \\
Scheme 2 & 85\% modified asphalt + 15\% TLA & Gradation 2 \\
Scheme 3 & & Gradation 3 \\
\hline Scheme 4 & & Gradation 1 \\
Scheme 5 & $70 \%$ modified asphalt + 30\% TLA & Gradation 2 \\
Scheme 6 & & Gradation 3 \\
\hline
\end{tabular}

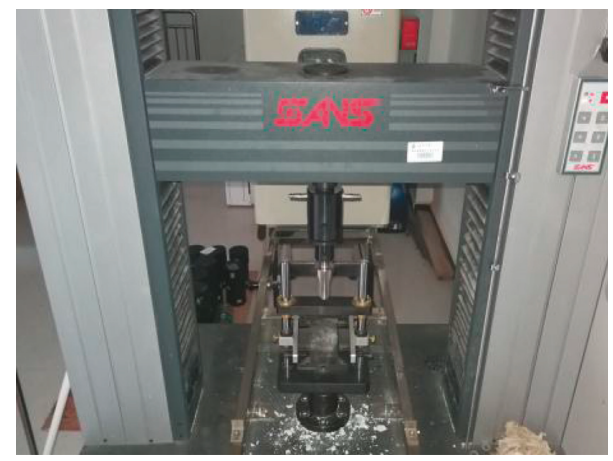

FIgURE 4: Electronic universal testing machine.

2.3.3. Low-Temperature Splitting Test. Low-temperature splitting tests were performed using an electronic universal testing machine. $101.6 \times 63.5 \mathrm{~mm}^{2}$ standard Marshall specimens were placed in a constant temperature flume for 1.5 hours at $-10^{\circ} \mathrm{C}$. A $100 \mathrm{kN}$ load was applied at $1 \mathrm{~mm} / \mathrm{min}$ until the specimens were destroyed. The maximum load and failure strain were recorded.

The splitting strength, ultimate tensile strain, and damage stiffness modulus were calculated, respectively, using the following equations [28]:

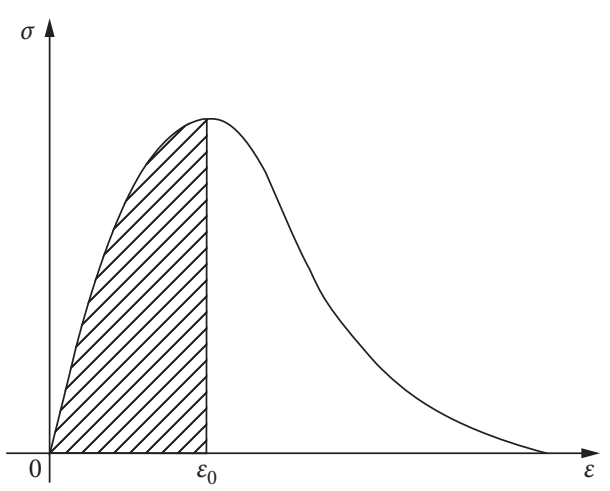

FIGURE 5: Stress-strain curve obtained from a low-temperature bending test.

$$
\begin{aligned}
\sigma_{\mathrm{T}} & =0.006287 \frac{P}{h}, \\
\varepsilon_{\mathrm{T}} & =x_{\mathrm{T}}\left(\frac{0.0307+0.0936 \mu}{1.35+5 \mu}\right), \\
S_{\mathrm{T}} & =P \times \frac{0.27+1.0 \mu}{h x_{\mathrm{T}}},
\end{aligned}
$$

where $\sigma_{\mathrm{T}}$ is the splitting strength $(\mathrm{MPa}), \varepsilon_{\mathrm{T}}$ is the ultimate tensile strain, $S_{\mathrm{T}}$ is the damage stiffness modulus ( $\left.\mathrm{MPa}\right), P$ is the damage load $(\mathrm{N}), h$ is the specimen height $(\mathrm{mm})$, and $\mu$ is Poisson's ratio ( $\mu=0.25$ when the test temperature was less than $\left.10^{\circ} \mathrm{C}\right) \cdot x_{\mathrm{T}}$ is the transverse total deformation during failure loading $(\mathrm{mm})$, where $x_{\mathrm{T}}=y_{\mathrm{T}}(0.135+0.5 \mu) /$ $(1.794-0.0314 \mu)[24,28]$. The test was repeated five times.

\section{Results and Analysis}

3.1. Using Ultimate Bending Strain Energy Density to Evaluate Low-Temperature Performance. The bending tensile 
strength, bending tensile strain, and ultimate bending strain energy density in the six test schemes were obtained from low-temperature bending tests, as shown in Figure 6.

Figure 6(a) shows that the best low-temperature performance is observed in Scheme 1 when the bending tensile strength is used to evaluate the low-temperature performance of GA. The bending tensile strength values in Schemes 2 through 6 are $12.21 \%, 4.81 \%, 26.64 \%, 28.13 \%$, and $7.33 \%$ lower than the bending tensile strength in Scheme 1, respectively.

Figure 6(b) shows that the best low-temperature performance is observed in Scheme 3 when the bending tensile strain is taken as the evaluation index. The bending tensile strain values in Schemes 1, 2, 4, 5, and 6 are 9.01\%, 21.60\%, $23.39 \%, 35.51 \%$, and $14.24 \%$ lower than those in Scheme 3, respectively.

The bending tensile strength and strain results are inconsistent. This inconsistency arises because crack formation in GA at low temperature is related to the strength of the material and its deformability. If the material is highly deformable, it will not crack easily even if its strength is low. Therefore, using only the bending tensile strength or strain to evaluate the low-temperature crack resistance of an asphalt mixture has some limitations.

Figure 6(c) shows that the best low-temperature performance is observed in Scheme 3 when the ultimate bending strain energy density is taken as the evaluation index. The strain energy density values in Schemes 1, 2, 4, 5, and 6 are $15.76 \%, 27.42 \%, 26.85 \%, 40.29 \%$, and $20.61 \%$ lower than those in Scheme 3, respectively. The corresponding strain energy density of gradations 1,2 , and 3 decreased to $32.82 \%, 25.00 \%$, and $18.51 \%$ when the TLA content increased from $15 \%$ to $30 \%$, respectively. It can be seen that the low-temperature performance of GA decreases significantly as the TLA blending ratio increases. This is because ash content in TLA significantly affects the low-temperature performance, which degrades the low-temperature performance of GA at high TLA blending ratio. At a given TLA mixing ratio, gradation 3 exhibits the best low-temperature performance. The strain energy density of gradations 1 and 2 is $7.38 \%$ and $25.59 \%$ lower than that of gradation 3 at $15 \%$ TLA blending ratio, as well as $23.67 \%$ and $31.52 \%$ lower than that of gradation 3 at $30 \%$ TLA blending ratio, respectively. This is because cohesion between fine particles is better than that between coarse particles. Crack development is hindered in material with fine particles. A crack in a sample with a higher content of fine aggregate requires more energy to expand to the same depth. However, when the total content of fine aggregate is too large, the low-temperature crack resistance of the mixture will be affected by uneven shrinkage of coarse and fine aggregate. Therefore, gradation 3 has the best anticracking performance at low temperature due to the passing rate through $1.18 \mathrm{~mm}$ and $2.36 \mathrm{~mm}$ sieve holes.

3.2. Using Bending Creep Rate to Evaluate Low-Temperature Performance. The GA creep rate was measured in each test scheme, and the results are shown in Figure 7.
Figure 7 shows that the best low-temperature performance is observed in Scheme 3 when the bending creep rate is taken as the evaluation index. The bending creep rate in Schemes 1, 2, 4, 5, and 6 is $2.74 \%, 8.14 \%, 15.95 \%, 19.19 \%$, and $5.65 \%$ lower than the value in Scheme 3, respectively. The results are consistent with those obtained from evaluating the ultimate bending strain energy density. When the proportion of TLA increased from $15 \%$ to $30 \%$, the bending creep rate for gradations 1,2 , and 3 decreased to $11.36 \%$, $10.98 \%$, and $5.65 \%$, respectively. For a given TLA blending ratio, the low-temperature performance for different mixing levels agrees with the results obtained from the bending strain energy evaluation.

3.3. Using Damage Stiffness Modulus to Evaluate LowTemperature Performance. The splitting strength, ultimate tensile strain, and damage stiffness modulus from the six schemes were obtained from low-temperature splitting tests. The results are shown in Figure 8.

The low-temperature splitting test results show that a greater damage stiffness modulus degrades the deformation capacity of the mixture, increasing the likelihood of fracture. In other words, the low-temperature performance is worse. Therefore, the damage stiffness modulus was selected as the evaluation index. Figure 8(c) shows that the damage stiffness modulus of gradations 1,2 , and 3 increases by $23.78 \%$, $23.53 \%$, and $6.60 \%$ when the TLA content increases from $15 \%$ to $30 \%$, respectively. Scheme 3 exhibits the best lowtemperature performance. The damage stiffness moduls from Schemes 1, 2, 4, 5, and 6 is $3.40 \%, 10.74 \%, 27.98 \%$, $36.79 \%$, and $6.60 \%$ higher than the values from Scheme 3, respectively. This is consistent with the results from the lowtemperature bending tests and bending creep tests.

\section{Low-Temperature Evaluation Index for GA in Cold Regions}

4.1. Evaluation Methods for Existing Asphalt Mixtures. According to "Specification for Design of Highway Asphalt Pavement" of China [29], the limit bending tensile strain obtained from a low-temperature bending test is currently used as the evaluation index of low-temperature crack resistance in asphalt mixtures. It is also used to evaluate the low-temperature performance of GA in China [24]. The specific requirements are shown in Table 6.

\subsection{Sensitivity Analysis between Low-Temperature Evaluation} Indicators. The test results show that the bending tensile strain, bending strain energy density, bending creep rate, and damage stiffness modulus exhibit the same evaluation results for different types of GA at low temperature. However, the sensitivity of the four indicators to different TLA content and gradation variations are different. The selected evaluation index should be sufficiently different for various types of GA, which can highlight the differences of low-temperature properties. Therefore, we analyzed the sensitivity of the 4 indices to different types of GA at low temperature. 


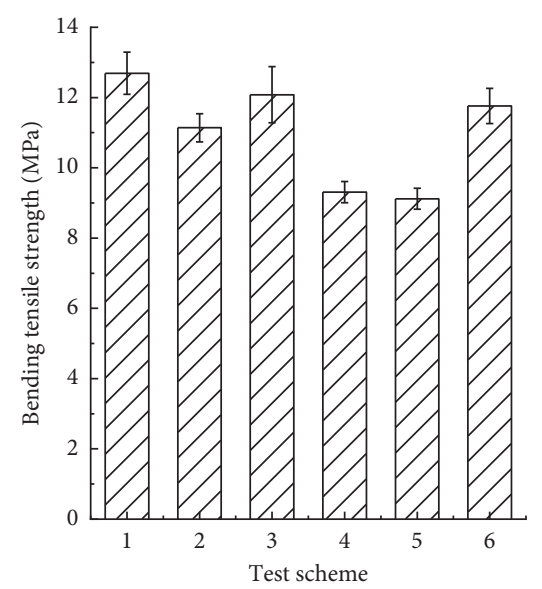

(a)

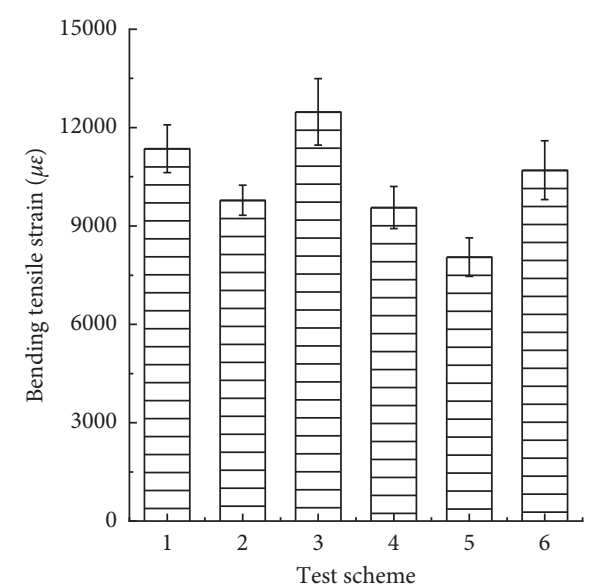

(b)

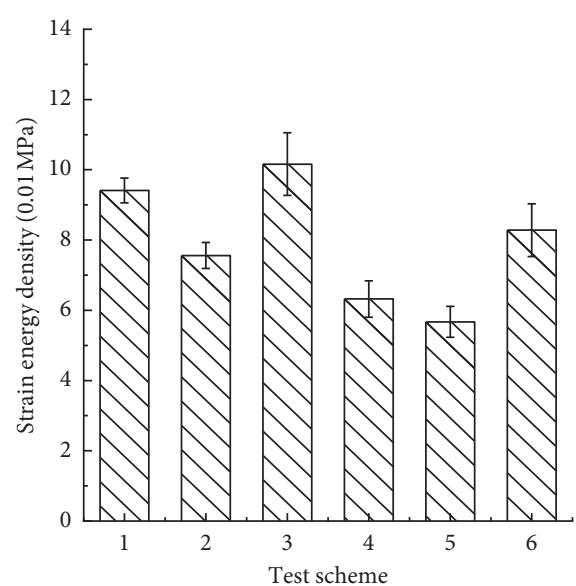

(c)

FIGURE 6: Low-temperature bending test results from the different test schemes. (a) Bending tensile strength, (b) bending tensile strain, and (c) ultimate bending strain energy density.

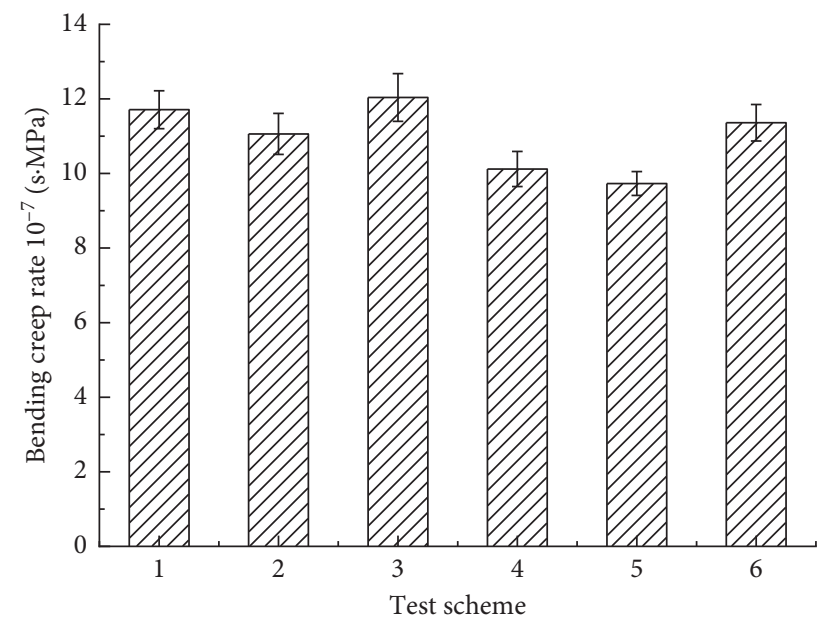

FIGURE 7: Bending creep rate histogram.

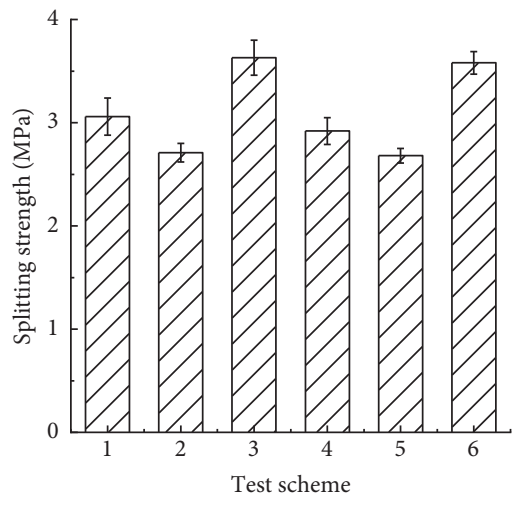

(a)

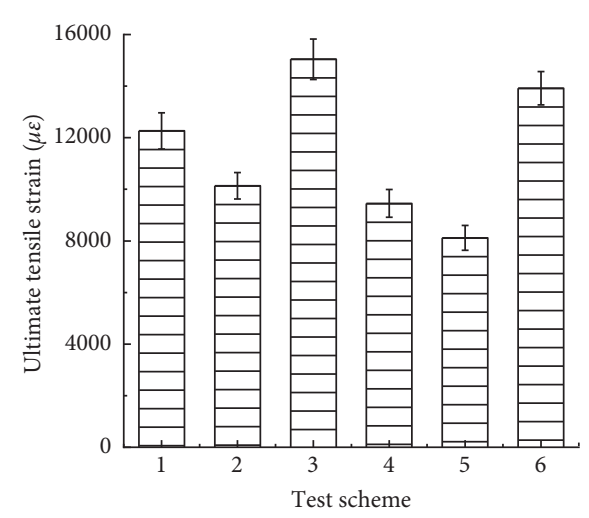

(b)

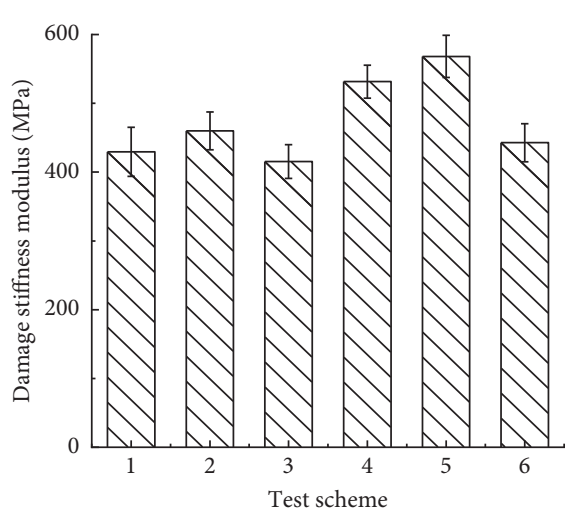

(c)

FIGURE 8: Low-temperature splitting test results. (a) Splitting strength, (b) ultimate tensile strain, and (c) damage stiffness modulus. 
TABLE 6: Low-temperature GA requirements [24].

\begin{tabular}{lccc}
\hline Climatic conditions in & $\begin{array}{c}-37 \sim-21.5 \\
\text { Colder } \\
\text { area in } \\
\text { winter }\end{array}$ & $\begin{array}{c}\text { Cold area } \\
\text { in winter }\end{array}$ & $\begin{array}{c}\text { Warm area } \\
\text { in winter }\end{array}$ \\
\hline $\begin{array}{l}\text { Limit bending tensile strain } \\
\text { of low-temperature } \\
\text { bending }\left(-10^{\circ} \mathrm{C}, 50 \mathrm{~mm} / \varepsilon\right)\end{array}$ & $\geq 9 \times 10^{-3}$ & $\geq 8 \times 10^{-3}$ & $\geq 7 \times 10^{-3}$ \\
\hline
\end{tabular}

The sensitivity of the low-temperature evaluation index for a mixture is calculated using the following equation [30]:

$$
\operatorname{sen}\left(\frac{\mu_{i}}{x_{j}}\right)=\left|\frac{\mu_{i+1}-\mu_{i}}{\mu_{i}}\right|,
$$

where $\operatorname{sen}\left(\mu_{i} / x_{j}\right)$ is the sensitivity of the low-temperature evaluation index $\mu$ and $\mu_{i}$ is the value of scheme $i$.

The results of four indices are shown in Table 7 .

Table 7 shows that variations in strain energy density are most distinguishable for different types of GA, followed by bending tensile strain, while variations in the bending creep rate are least distinguishable. According to the sensitivity analysis, bending strain energy density is more sensitive than bending tensile strain to distinguish GA with different gradation and TLA content. Therefore, the bending strain energy density measured from low-temperature bending tests at $-10^{\circ} \mathrm{C}$ should be used as the low-temperature evaluation index of GA.

4.3. Correlation Analysis between Low-Temperature Evaluation Indicators. According to Section 4.1, the bending tensile strain is adopted as the evaluation index of low-temperature performance in Chinese code [24, 29]. Therefore, on the basis of analyzing the sensitivity of the indexes, we analyzed the correlation between strain energy density, bending creep rate, damage stiffness modulus, and bending tensile strain.

The bending tensile strain adopted in Chinese code was selected as the reference data, and the strain energy density, bending creep rate, and damage stiffness modulus were recorded for comparison. The correlation coefficient between each index and flexural strain was determined by calculating the grey relational coefficient.

After dimensionless processing of the data, the correlation coefficients between the reference sequence and the comparison sequence are calculated using

$$
\begin{aligned}
\gamma_{0 i}(m) & =\frac{\min _{i}\left[\min _{m} \Delta(m)\right]+\rho \max _{i}\left[\max _{m} \Delta(m)\right]}{\Delta_{i}(m)+\rho \max _{i}\left[\max _{m} \Delta(m)\right]}, \\
\Delta_{i}(m) & =\left|X_{0}^{\prime}(m)-X_{i}^{\prime}(m)\right|,
\end{aligned}
$$

where $\gamma_{0 i}(m)$ is the correlation coefficient of scheme $m$, $\min _{i}\left[\min _{m} \Delta(m)\right]$, and $\max _{i}\left[\max _{m} \Delta(m)\right]$ are the two-level minimum and maximum differences, respectively, and $\rho=$ 0.2 is the resolution coefficient.

The grey relational coefficients between the comparison and reference can be calculated using equation (4). The results are shown in Table 8.
TABLE 7: Sensitivity factor of each index.

\begin{tabular}{ccccc}
\hline & \multicolumn{5}{c}{ Sensitivity factor (\%) } \\
& $\begin{array}{c}\text { Bending } \\
\text { tensile } \\
\text { strain }\end{array}$ & $\begin{array}{c}\text { Strain } \\
\text { energy } \\
\text { density }\end{array}$ & $\begin{array}{c}\text { Bending } \\
\text { creep } \\
\text { rate }\end{array}$ & $\begin{array}{c}\text { Damage } \\
\text { stiffness } \\
\text { modulus }\end{array}$ \\
\hline 15\% TLA & & & & \\
Gradation 1 & - & - & - & - \\
Gradation 3 & 9.90 & 7.97 & 2.82 & 3.28 \\
Gradation 2 & 21.60 & 25.59 & 8.14 & 10.74 \\
30\% TLA & & & & \\
Gradation 2 & 17.74 & 25.00 & 12.03 & 23.53 \\
Gradation 3 & 32.97 & 46.03 & 16.75 & 22.07 \\
Gradation 1 & 10.66 & 23.67 & 10.92 & 20.06 \\
\hline
\end{tabular}

$$
\gamma_{i}=\frac{1}{n} \sum_{m=1}^{n} \gamma_{0 i}(m),
$$

where $\gamma_{i}$ is the grey relational coefficient between the comparison sequence and the reference sequence.

Table 8 shows that the strain energy density has the largest grey relational coefficient with bending tensile strain, followed by bending creep rate and damage stiffness modulus. The correlation between damage stiffness modulus and bending tensile strain is much smaller than the other two indices.

4.4. GA Strain Energy Density Control Standard. Through the analysis of sensitivity and correlation, strain energy density is finally used as the evaluation index to establish a functional relationship with the bending tensile strain required by the code [24]. Linear fitting was used to establish the relationship as shown in Figure 9. The fitting results are shown in Table 9. Snedecor's F-distribution was used to analyze variance in the data, as shown in Table 10 .

Tables 9 and 10 show that the $p$ value is 0.00119 , indicating that strain energy density is significantly correlated with bending tensile strain. The coefficient of determination between strain energy density and bending strain is $R^{2}=0.93039$, which indicates that the regression functions for the two indices fit well. The corresponding strain energy density in each section in Table 1 was calculated using the fitting function relating strain energy density and bending strain. The control standard for GA strain energy density is shown in Table 11.

\section{Storage Stability of GA in Cold Area}

GA production and construction are conducted at high temperature and in a lowoxygen environment; thus, it is difficult to qualitatively analyze performance degradation $[31,32]$. Therefore, the performance of GA prepared with different mixing times should be tested such that the transportation and storage requirements of GA in cold areas can be determined.

GA specimens were sampled from the special transport vehicle (COOKER) at the construction site of a steel box girder bridge deck project of Jining South Circle Highway in 
TABLE 8: Grey relational coefficients.

\begin{tabular}{lccc}
\hline & $\begin{array}{c}\text { Strain energy } \\
\text { density }\end{array}$ & $\begin{array}{c}\text { Bending } \\
\text { creep rate }\end{array}$ & $\begin{array}{c}\text { Damage stiffness } \\
\text { modulus }\end{array}$ \\
\hline $\begin{array}{l}\text { Grey relational } \\
\text { coefficient }\end{array}$ & 0.6988 & 0.6872 & 0.3944 \\
\hline
\end{tabular}

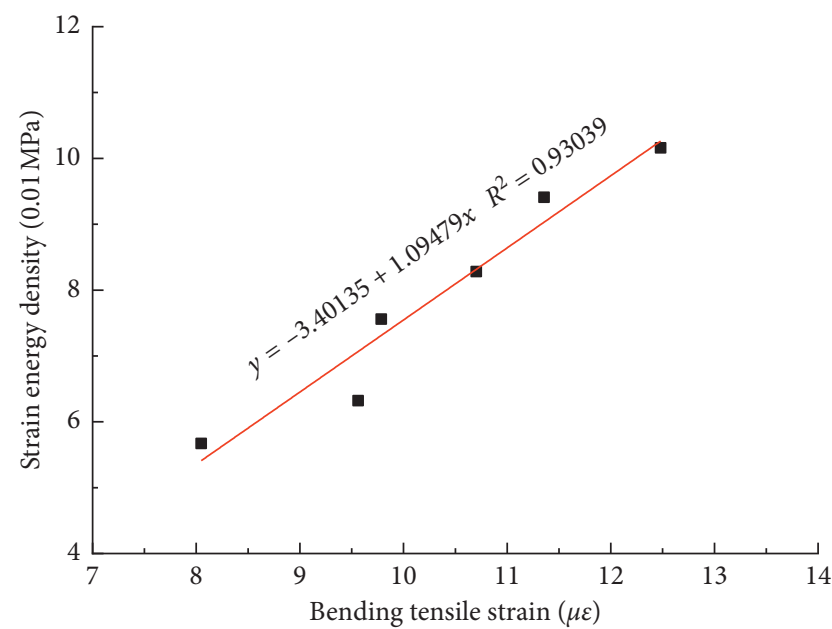

FIGURE 9: Fitting relationship between strain energy density and bending tensile strain.

TABLE 9: Fitting results.

\begin{tabular}{lcccc}
\hline & Value & $\begin{array}{c}\text { Standard } \\
\text { error }\end{array}$ & $t$ value & $p$ value \\
\hline Linear fitting & & & & \\
$y=\mathrm{A} x+\mathrm{B}$ & & & & \\
$\quad$ Intercept & -3.40135 & $1.3849 E 6$ & -2.45591 & 0.07 \\
$\quad$ Slope & 1.09479 & 0.13293 & 8.23568 & 0.00119 \\
$R^{2}$ & 0.93039 & & & \\
\hline
\end{tabular}

TABle 10: Analysis of variance.

\begin{tabular}{lccccc}
\hline & DF & $\begin{array}{c}\text { Sum of } \\
\text { square }\end{array}$ & $\begin{array}{c}\text { Mean } \\
\text { square }\end{array}$ & $F$ value & $p$ value \\
\hline Linear fitting & & & & & \\
$y=\mathrm{A} x+\mathrm{B}$ & & & & & \\
$\quad$ Model & 1 & 14.27514 & 14.27514 & 67.82637 & 0.00119 \\
$\quad$ Error & 4 & 0.84186 & 0.21047 & & \\
$\quad$ Total & 5 & 15.117 & & & \\
\hline
\end{tabular}

TABLE 11: GA strain energy density control standard in cold regions.

\begin{tabular}{lccc}
\hline $\begin{array}{l}\text { Climatic conditions in } \\
\text { winter }\left({ }^{\circ} \mathrm{C}\right)\end{array}$ & $\begin{array}{c}-37 \sim-21.5 \\
\text { Colder area } \\
\text { in winter }\end{array}$ & $\begin{array}{c}-21.5 \sim-9 \\
\text { Cold area } \\
\text { in winter }\end{array}$ & $\begin{array}{c}>-9 \\
\text { Warm area } \\
\text { in winter }\end{array}$ \\
\hline $\begin{array}{l}\text { Strain energy density } \\
\left(-10^{\circ} \mathrm{C}, 50 \mathrm{~mm}, 10^{-2} \mathrm{MPa}\right)\end{array}$ & $\geq 6.5$ & $\geq 5.5$ & $\geq 4.5$ \\
\hline
\end{tabular}

Wulanchabu City. The GA performance indices were tested for these specimens. GA continued mixing for a period of time in the COOKER truck before paving. Therefore, in order to simulate an actual paving situation, after initially mixing in the COOKER vehicle for 40 minutes, the mixture was regarded as GA after completion of the second mixing. The mixed GA was stored and stirred for 1 to $8 \mathrm{~h}$ in $1 \mathrm{~h}$ increments. The stored specimens were then used to test the fluidity of the mixture and form the specimen.

After standing for 1 day at room temperature, the formed specimens were tested for penetration, lowtemperature bending, and trabecular bending fatigue at $50^{\circ} \mathrm{C}$.

This article refers to the high-temperature evaluation method for GA in China and foreign countries. Penetration tests at $40^{\circ} \mathrm{C}$ are used as a high-temperature evaluation method in Germany. Penetration tests at $60^{\circ} \mathrm{C}$ were used to evaluate the high-temperature performance of GA from the Hong Kong-Zhuhai-Macao Bridge in China [30, 31]. In addition, the project operating temperature ranges from -25 to $50^{\circ} \mathrm{C}$, and the design temperature of the Hong Kong-Zhuhai-Macao Bridge ranges from 0 to $60^{\circ} \mathrm{C}$. Therefore, penetration tests at $50^{\circ} \mathrm{C}$ were used to evaluate the high-temperature performance of GA. The total penetration and penetration increment obtained from the test results were used as the hightemperature performance evaluation indices. The test was introduced in Section 2.2 and was conducted at a test temperature of $50^{\circ} \mathrm{C}$.

The fluidity, penetration at $50^{\circ} \mathrm{C}$, penetration increment at $50^{\circ} \mathrm{C}$, bending strain, strain energy density, and fatigue life obtained from the above tests are shown in Figure 10.

Figure 10(a) shows that the storage mixing time significantly affects the fluidity of GA. The aggregate and asphalt gradually mix evenly when stored/mixed from 1 to $4 \mathrm{~h}$, and the dispersion tends to be stable. The fluidity of GA fluctuates between 8 and $12 \mathrm{~s}$, showing good construction and workability, and fluidity is greatest when the storage/mixing time is $3 \mathrm{~h}$. Aging becomes obvious when the storage/mixing time exceeds $4 \mathrm{~h}$; the brittleness of the binder increases, and the fluidity decreases. Based on changes in GA fluidity, paving should be carried out within 5 to 5.5 hours after the completion of GA secondary mixing. The construction and workability requirements will not be met if the storage/mixing time exceeds 6 hours.

The GA penetration and increment results in Figure 10(b) show a downward trend when the stirring time is less than $4 \mathrm{~h}$, indicating that the aging rate of GA is greater than the performance decay rate. When the storage/mixing time exceeds $4 \mathrm{~h}$, GA penetration and its increment increase rapidly. This indicates that the material performance decay rate has exceeded the aging rate, thus degrading high temperature stability. The best spreading time of GA is between 3 and $4 \mathrm{~h}$ after the second stirring.

Figure 10(c) shows that the bending strain and strain energy density of GA decrease as the mixing time increases. This is primarily due to the volatilization of light components in GA in the ultrahot and hypoxic environment, thus hardening of the asphalt binder and decreasing cohesion. Figure 10(c) shows that the storage/stirring time has a minor influence on bending strain. The bending strain decreases 


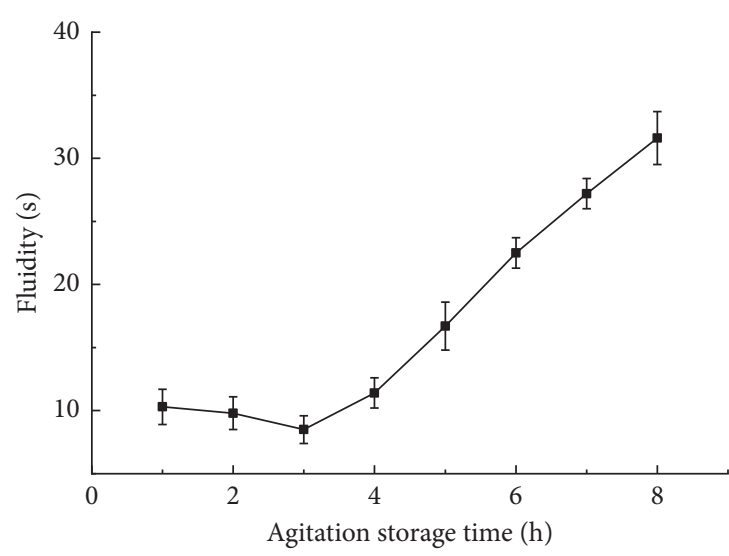

(a)

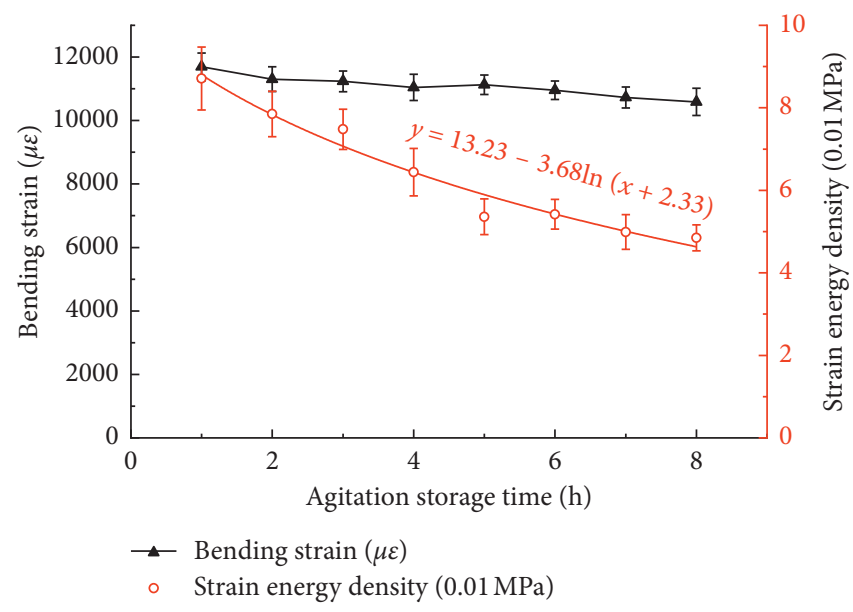

(c)

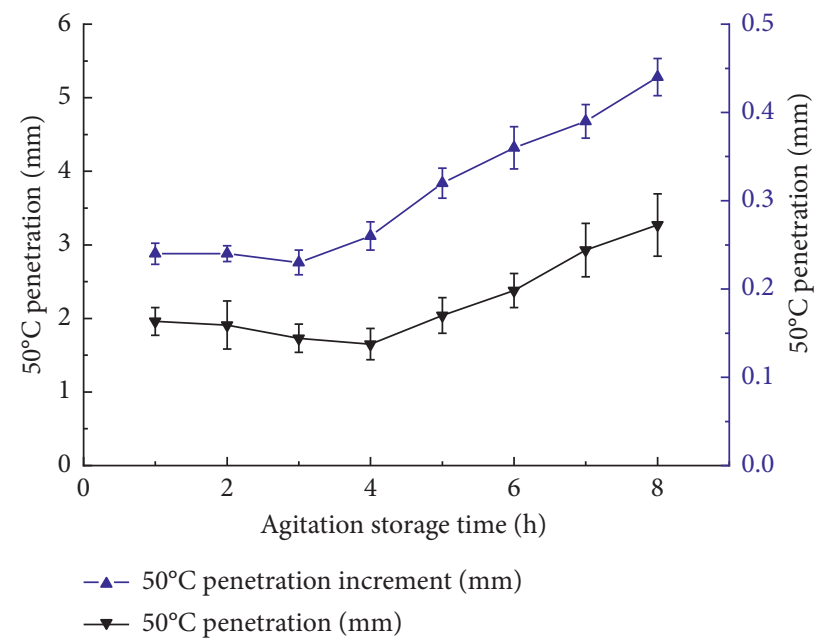

(b)

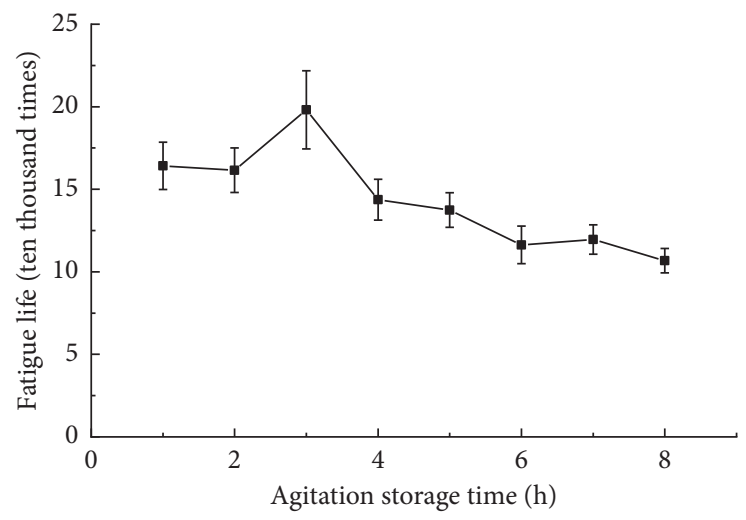

(d)

FIGURE 10: GA performance results for different storage and stirring times. (a) Fluidity, (b) penetration and penetration increment, (c) bending tensile strain and strain energy density, and (d) fatigue life.

from 11690 to 10587 when the storage time is extended from 1 to $8 \mathrm{~h}$. This bending strain value still meets the standard use requirements.

The storage time has a significant effect on the strain energy density. The strain energy density decreases from 8.71 $\mathrm{MPa}$ to $4.85 \mathrm{MPa}$ when the storage time increases from 1 to $8 \mathrm{~h}$. The relationship between strain energy density and storage time is shown in Figure 10(c). Considering the low-temperature index requirement in Table 12 and the strain energy density, paving construction should be completed within 5.2 hours after the completion of secondary mixing.

Figure 10(d) shows that the fatigue life of GA initially increases and then decreases as stirring time increases. The fatigue life reaches its maximum value when the stirring time is $3 \mathrm{~h}$. This is because the fatigue life of GA is affected by mixing uniformity and aging. The fatigue life increases gradually when mixing is more uniform. The homogeneity of the GA mix before 3 hours has a major effect on fatigue life. GA gradually mixes evenly as the storage time increases and reaches the best mixing effect at 3 hours; thus, the fatigue
TABLE 12: GA storage/mixing time requirements in cold regions.

\begin{tabular}{lccc}
\hline $\begin{array}{l}\text { Climatic conditions in } \\
\text { winter }\left({ }^{\circ} \mathrm{C}\right)\end{array}$ & $\begin{array}{c}-37 \sim-21.5 \\
\text { Colder area } \\
\text { in winter }\end{array}$ & $\begin{array}{c}-21.5 \sim-9 \\
\text { Cold area } \\
\text { in winter }\end{array}$ & $\begin{array}{c}>-9 \\
\text { Warm area } \\
\text { in winter }\end{array}$ \\
\hline $\begin{array}{l}\text { Construction storage } \\
\text { stirring time }(\leq)\end{array}$ & $3 \mathrm{~h}$ & $4 \mathrm{~h}$ & $5.5 \mathrm{~h}$ \\
\hline
\end{tabular}

life is maximized. After 3 hours, aging primarily affects the fatigue life. GA gradually ages and the fatigue life decreases as the storage time increases. The fatigue life of GA reduces as the stirring times increases. Among them, the fatigue life corresponding to the " $3 \mathrm{~h}$ to $4 \mathrm{~h}$ " and " $5 \mathrm{~h}$ to $6 \mathrm{~h}$ " sections is most obvious. In order to ensure the fatigue performance of GA, the GA mixing and storage times should be reduced to as low as possible during construction.

In summary, considering the fluidity, strain energy density, high-temperature performance, and fatigue life of GA, the recommended GA technical requirements after completion of secondary stirring are shown in Table 12. 


\section{Conclusions}

Low-temperature bending, bending creep, and splitting test results were used to evaluate the low-temperature performance of two kinds of TLA admixtures and three types of GA gradations. The low-temperature evaluation index of GA in cold regions was obtained from our test results. Degradation of the performance of GA mixtures after secondary mixing was studied.

(1) The result shows that the low-temperature performance of GA decreases as the TLA content increases. The low-temperature performance of a fine gradation is better than that of a coarse gradation. The performance can be improved by adjusting the aggregate passing rate through $1.18 \mathrm{~mm}$ and $2.36 \mathrm{~mm}$ sieve holes.

(2) The sensitivity of bending tensile strain, bending strain energy density, bending creep rate, and damage stiffness modulus to different types of GA were analyzed. And the grey correlation analysis of bending tensile strain and other index was carried out. We recommend that strain energy density be used as a low-temperature evaluation index for GA in cold regions.

(3) The degradation of GA performance after secondary mixing at high temperatures is in lowoxygen conditions was studied. Strain energy density was taken as the main control index while considering the fluidity, high-temperature performance, and fatigue requirements of GA. The storage mixing time required during GA transportation in cold areas was recommended based on these results.

\section{Data Availability}

The test data used to support the findings of this study have been deposited in the Hindawi (Advance in Materials Science and Engineering) repository. The test data are included within the article and can be made freely available.

\section{Conflicts of Interest}

The authors declare no conflicts of interest.

\section{Acknowledgments}

This research was funded by Construction of Science and Technology Projects by the Ministry of Communications of China (2013 318 J08 220) and the Inner Mongolia Autonomous Region Transportation Science and Technology Project of China (NJ-2018-23).

\section{References}

[1] C. H. Wang, Q. Li, K. C. P. Wang, X. L. Sun, and X. C. Wang, "Emission reduction performance of modified hot mix asphalt mixtures," Advances in Materials Science and Engineering, vol. 2017, Article ID 2506381, 11 pages, 2017.
[2] H. Wang and G. Li, "Study of factors influencing gussasphalt mixture performance," Construction and Building Materials, vol. 101, pp. 193-200, 2015.

[3] B. Behnia, W. Buttlar, and H. Reis, "Evaluation of lowtemperature cracking performance of asphalt pavements using acoustic emission: a review," Applied Sciences, vol. 8, no. 2, p. 306, 2018.

[4] Y. Liu, Z. D. Qian, J. Hu, and L. Jin, “Temperature behavior and stability analysis of orthotropic steel bridge deck during gussasphalt pavement paving," Journal of Bridge Engineering, vol. 23, no. 1, article 04017117, 2018.

[5] C. H. Wang, Q. Cheng, Z. W. Gao et al., "Review on status and development of gussasphalt concrete," Materials Review, vol. 31, no. 9, pp. 135-145, 2017.

[6] S. Luo, Q. Lu, Z. Qian, H. Wang, and Y. Huang, "Laboratory investigation and numerical simulation of the rutting performance of double-layer surfacing structure for steel bridge decks," Construction and Building Materials, vol. 144, pp. 178-187, 2017.

[7] F. X. Xie, D. J. Zhang, A. Zhou, B. Ji, and L. Chen, "On the viscoelastic parameters of gussasphalt mixture based on modified burgers model: deviation and experimental verification," Advances in Materials Science and Engineering, vol. 2017, Article ID 4324765, 11 pages, 2017.

[8] S. Luo, Z. Qian, X. Yang, and H. Wang, "Design of gussasphalt mixtures based on performance of gussasphalt binders, mastics and mixtures," Construction and Building Materials, vol. 156, pp. 131-141, 2017.

[9] B. Ma, X.-Y. Zhou, J. Liu, Z. You, K. Wei, and X.-F. Huang, "Determination of specific heat capacity on composite shape-stabilized phase change materials and asphalt mixtures by heat exchange system," Materials, vol. 9, no. 5, p. $389,2016$.

[10] J.-S. Chen, M.-C. Liao, C.-C. Huang, and C.-H. Wang, "Fundamental characterization of engineering properties of gussasphalt mixtures," Journal of Materials in Civil Engineering, vol. 23, no. 12, pp. 1719-1726, 2011.

[11] Y. Tan, L. Zhang, and H. Xu, "Evaluation of low-temperature performance of asphalt paving mixtures," Cold Regions Science and Technology, vol. 70, pp. 107-112, 2012.

[12] M. Pszczola, M. Jaczewski, D. Rys, P. Jaskula, and C. Szydlowski, "Evaluation of asphalt mixture lowtemperature performance in bending beam creep test," Materials, vol. 11, no. 1, p. 100, 2018.

[13] S. P. Fan, H. Wang, H. Z. Zhu, and W. Sun, "Evaluation of self-healing performance of asphalt concrete for lowtemperature fracture using semicircular bending test," Journal of Materials in Civil Engineering, vol. 30, no. 9, article 04018218, 2018.

[14] S. P. Wu, T. G. Liu, L. Pang, T. W. Cao, and P. Pan, "Study of high temperature performance and low temperature property on layered silicate modified asphalt concrete," Key Engineering Materials, vol. 509, pp. 189-193, 2012.

[15] C. M. Gao, S. Han, S. Chen, and H. Li, "Research on Basalt fiber asphalt concrete's low temperature performance," Applied Mechanics and Materials, vol. 505-506, pp. 35-38, 2014.

[16] F. Morea, J. O. Agnusdei, and R. Zerbino, "The use of asphalt low shear viscosity to predict permanent deformation performance of asphalt concrete," Materials and Structures, vol. 44, no. 7, pp. 1241-1248, 2010.

[17] J. J. Pei, Q. L. Guo, and J. L. Pang, "Experimental research on low temperature crack resistance of steel fiber asphalt concrete," in Proceedings of the 2016 5th International Conference 
on Sustainable Energy and Environment Engineering (ICSEEE 2016), vol. 63, pp. 145-150, Zhuhai, China, November 2016.

[18] P. W. Hao and Z. L. Liu, "Study on thermal stress restrained specimen test of asphalt mixture," Petroleum Asphalt, vol. 1, pp. 9-11, 2002.

[19] J. Yang, Y. Q. Pan, and X. J. Deng, "Gussasphalt performances on bridge deck," Journal of Traffic and Transportation Engineering, vol. 1, pp. 49-53, 2007.

[20] H. Liu, P. Hao, and J. Xu, "Effects of nominal maximum aggregate size on the performance of stone matrix asphalt," Applied Sciences, vol. 7, no. 2, p. 126, 2017.

[21] S. Luo, Z. D. Qian, and X. Yang, "Laboratory evaluation of double-layered pavement structures for long-span steel bridge decks," Journal of Materials in Civil Engineering, vol. 30, no. 6, article 04018111, 2018.

[22] C. Wang, X. Yang, Q. Li, T. Guo, and T. Jiang, "Preparation and performance of conductive gussasphalt concrete," Transportmetrica A: Transport Science, vol. 14, no. 5, pp. 1-16, 2018.

[23] J. Qian, Q. Wang, W. Wu, and H. Zhang, "Fatigue performance of gussasphalt concrete made from modified AH-70\# asphalt," Materials \& Design (1980-2015), vol. 52, pp. 686-692, 2013.

[24] China Merchants Chongqing Communications Technology Research \& Design Institute, Guidelines for Pavement Design and Construction Technology of Highway Steel Box Girder Bridge Deck, China Communications Press, Beijing, China, 2006.

[25] G. Y. Zhao, Q. Shao, and D. B. Yan, "Gradation performance of gussasphalt mixture for steel bridge deck paving," Journal of Highway and Transportation Research and Development, vol. 30, no. 6, pp. 75-80, 2013.

[26] Maruzen-Yushodo, A Brief Survey of Paving Test Method, Japan Road Association, Tokyo, Japan, 1992.

[27] R. Zhang, X. M. Huang, and Y. L. Zhao, "Design of gussasphalt gradation," Journal of Southeast University (Natural Science Edition), vol. 47, no. 4, pp. 661-665, 2007.

[28] Ministry of Communications of the People's Republic of China, JTG E20 Standard Test Methods of Bitumen and Bituminous Mixtures for Highway Engineering, China Communications Press, Beijing, China, 2011.

[29] Ministry of Communications of the People's Republic of China, JTG D50 Specification for Design of Highway Asphalt Pavement, China Communications Press, Beijing, China, 2017.

[30] X. L. Li, L. Y. Shan, and Y. Q. Tan, "Analysis of different indices for high- and low-temperature properties of asphalt binder," Construction and Building Materials, vol. 83, pp. 70-76, 2015.

[31] T. T. Wan and N. C. Wu, "Research on design of poured asphalt concrete for steel deck," Road Machinery \& Construction Mechanization, vol. 32, no. 2, pp. 81-87, 2015.

[32] W. G. Zhang, Z. R. Jia, Y. X. Zhang et al., "The effect of directto-plant styrene-butadiene-styrene block copolymer components on Bitumen modification," Polymers, vol. 11, no. 1, p. 140, 2019. 


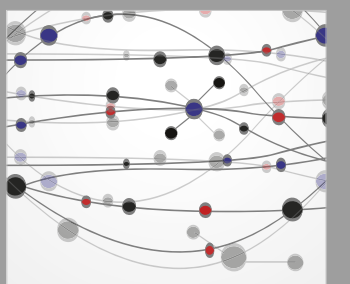

The Scientific World Journal
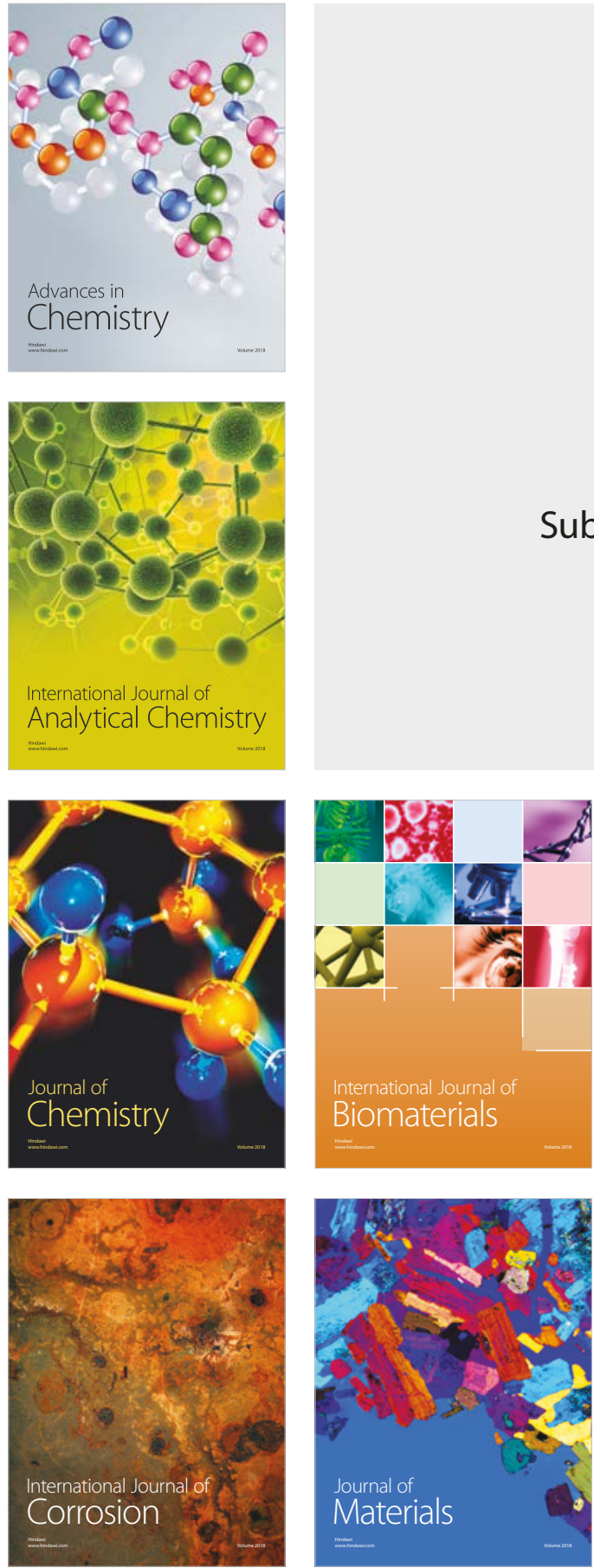

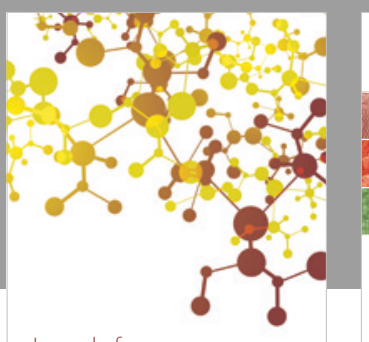

Journal of

Applied Chemistry
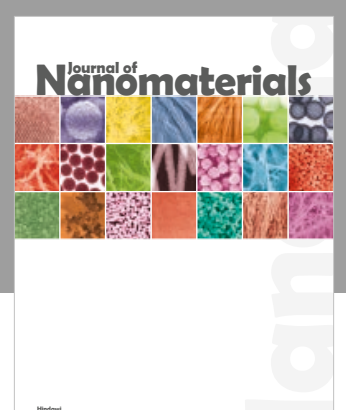

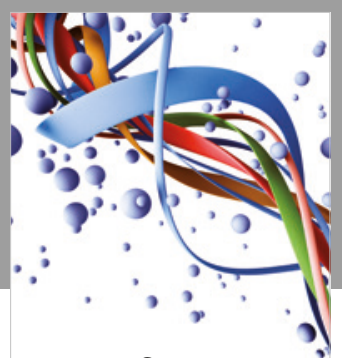

Scientifica

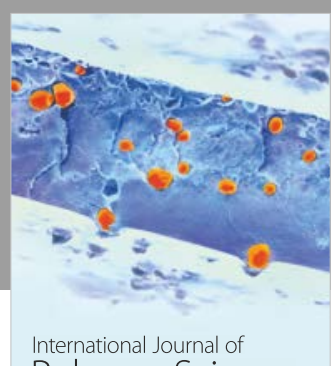

Polymer Science

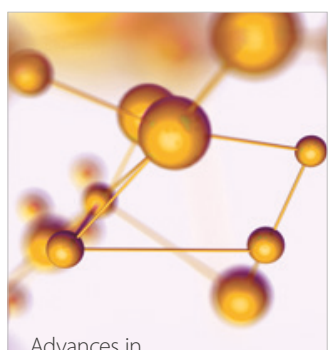

Physical Chemistry
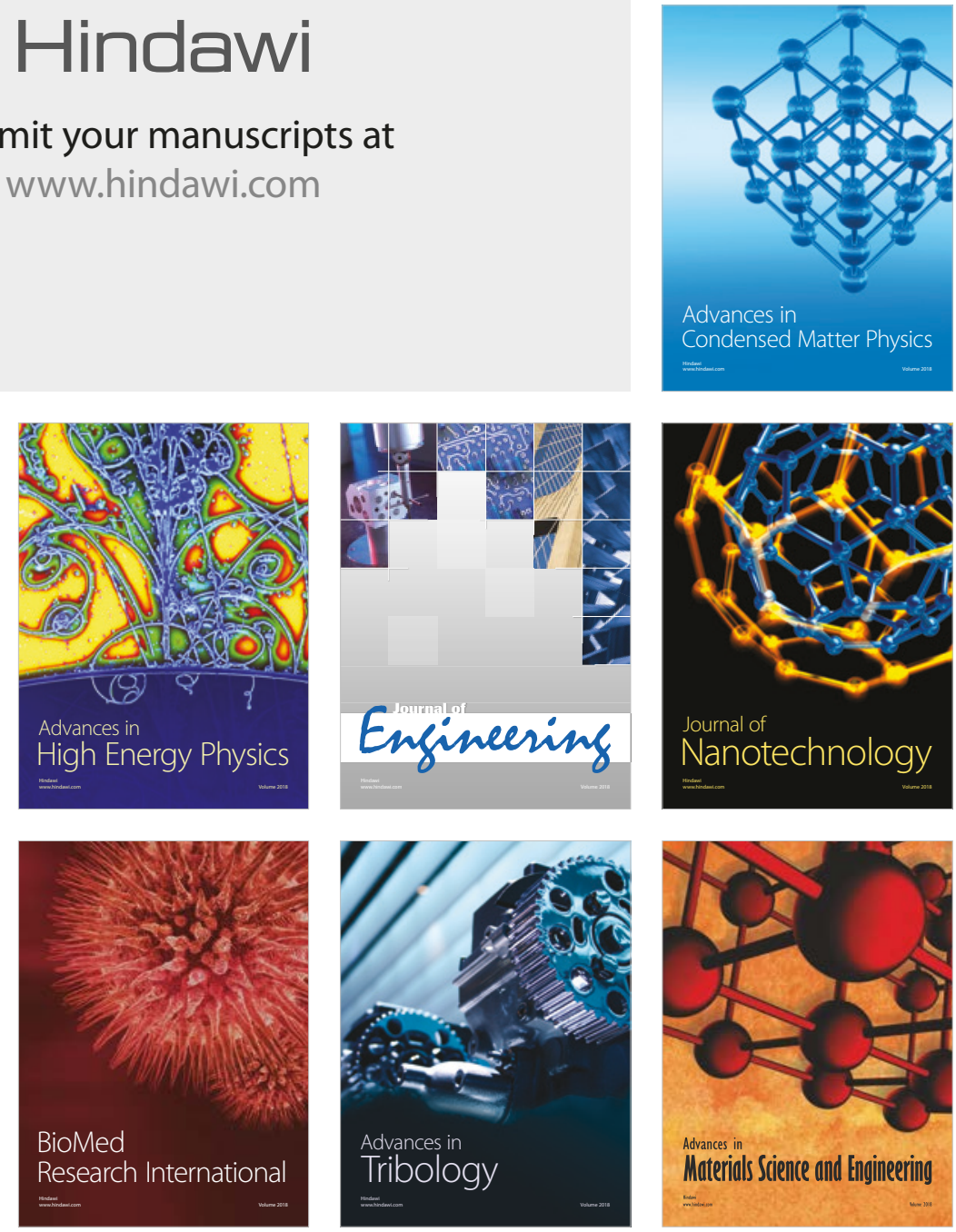